\title{
Incidence and Prevalence of Antiepileptic Medication Use in Community-Dwelling Persons with and without Alzheimer's Disease
}

\author{
Tatyana Sarycheva ${ }^{\mathrm{a}, \mathrm{b}, *}$, Heidi Taipale ${ }^{\mathrm{a}, \mathrm{b}, \mathrm{c}}$, Piia Lavikainen ${ }^{\mathrm{a}, \mathrm{b}}$, Jari Tiihonen ${ }^{\mathrm{c}, \mathrm{d}}$, Antti Tanskanen ${ }^{\mathrm{c}, \mathrm{d}}$, \\ Sirpa Hartikainen ${ }^{\mathrm{a}, \mathrm{b}}$ and Anna-Maija Tolppanen ${ }^{\mathrm{a}}$ \\ ${ }^{a}$ School of Pharmacy, Faculty of Health Sciences, University of Eastern Finland, Kuopio, Finland \\ ${ }^{\mathrm{b}}$ Kuopio Research Centre of Geriatric Care, University of Eastern Finland, Kuopio, Finland \\ ${ }^{\mathrm{c}}$ Department of Clinical Neuroscience, Karolinska Institutet, Stockholm, Sweden \\ ${ }^{\mathrm{d}}$ Department of Forensic Psychiatry, Niuvanniemi Hospital, University of Eastern Finland, Kuopio, Finland
}

Accepted 16 August 2018

\begin{abstract}
.
Background: Although antiepileptic drugs (AEDs) have a potential for adverse drug reactions in older populations, little is known about their use in relation to Alzheimer's disease (AD) diagnosis.

Objectives: In this study, we investigated the incidence and prevalence of AED use in relation to AD diagnosis.

Methods: The MEDALZ-study includes all Finnish persons who received clinically verified AD diagnoses $(n=70,718)$ during 2005-2011 and a matched comparison cohort without AD $(n=70,718)$. AD diagnoses were identified from the Special Reimbursement Register. We used the Prescription Register to identify dispensed AEDs. Incident AED users were identified with a one-year washout period 9-10 years before AD diagnosis, and incidence rates per 100 person-years were calculated for each six-month period from nine years before to five years after AD diagnosis. Prevalence was assessed as proportion using AEDs during each six-month time period for incident use.

Results: Persons with AD were more likely to use AEDs during the study period (4.3\%) than persons without AD (3.2\%). The incidence and prevalence of AED use was higher among persons with AD and increased around the time of AD diagnosis. Epilepsy diagnoses did not explain these differences. Persons with AD were more likely to use older AEDs.

Conclusion: Our study highlights the need to balance effective symptom control with the possible risks of treatment.
\end{abstract}

Keywords: Alzheimer's disease, antiepileptic drugs, dementia, incidence, prevalence

\section{INTRODUCTION}

Use of antiepileptic drugs (AEDs) is relatively common [1-4]. Still, only one previous study has

\footnotetext{
${ }^{*}$ Correspondence to: Tatyana Sarycheva, MD, Faculty of Health Sciences, School of Pharmacy, University of Eastern Finland, PO Box 1627, FI-70211, Kuopio, Finland. Tel.: +358 50434 9807; E-mail: tatyana.sarycheva@uef.fi.
}

assessed the use of AEDs among persons with Alzheimer's disease (AD) [5]. In that study, persons with $\mathrm{AD}$ were more likely to use older AEDs than those without AD.

To the best of our knowledge, there are no previous studies concerning the AED utilization patterns with the focus on the incidence and prevalence in relation to $\mathrm{AD}$ diagnosis. AED use in persons with $\mathrm{AD}$ or other dementive disorders is related to higher risk 
of adverse drug effects and drug-drug interactions especially in the case of older antiepileptics $[6,7]$.

We performed a nationwide study in a cohort of all community-dwelling residents who received a clinically verified $\mathrm{AD}$ diagnosis in Finland in 2005-2011. Our aims were to estimate the incidence and prevalence of AED use among persons with $A D$ in comparison to persons without $\mathrm{AD}$.

\section{MATERIALS AND METHODS}

\section{Study population}

This study is based on a nationwide register-based MEDALZ (Medication use and Alzheimer's disease) cohort study. MEDALZ includes all communitydwelling persons residing in Finland who received diagnoses of AD during 2005-2011 $(\mathrm{N}=70,718)$ [8]. The age range of the study cohort was 35-105 years (mean age $80.1 \pm 7.1$ years) and $65.2 \%$ of the study population were women. Clinically verified AD diagnoses have been identified from the Special Reimbursement Register maintained by the Social Insurance Institution of Finland (SII). This register contains records of persons who are entitled for higher medication reimbursement due to chronic diseases. All citizens and long-term residents of Finland are covered under the Finnish National Health Insurance (NHI) scheme and are thus eligible for reimbursement of medical expenses under the Health Insurance Act.

To be entitled for a special reimbursement due to a chronic disease, a patient must meet predefined criteria and a diagnosis statement must be submitted to the SII for approval. The duration of the approval process is eliminated as the original date of application for Special Reimbursement is recorded as the date of diagnosis in that register. For AD, the SII requires that the medical statement verifies that the patient has: 1) symptoms consistent with $\mathrm{AD}$; 2) experienced a decrease in social capacity over a period of at least 3 months; 3) received a computed tomography(CT)/magnetic resonance imaging scan (MRI); 4) had possible alternative diagnoses excluded; and 5) received confirmation of the diagnosis by a registered geriatrician or neurologist. The SII reviews all medical statements and gives special reimbursement if the criteria are fulfilled. The diagnosis of AD is based on the National Institute of Neurological and Communicative Disorders and Stroke and the Alzheimer's Disease and Related Disorders Association [9] and DSM-IV criteria for Alzheimer's disease.
According to Finnish legislation, no ethics committee approval was required for this study because only pseudonymized register-based data were used and the study participants were not contacted.

In order to compare the antiepileptic drug use among persons with $\mathrm{AD}$ to those without $\mathrm{AD}$, a cohort of community-dwelling persons without $\mathrm{AD}$ was identified from a register that includes everyone who is covered by the NHI. Each person with AD was matched with a person without $\mathrm{AD}(\mathrm{N}=70,718)$ according to age, gender, and region of residence at the date of $\mathrm{AD}$ diagnoses (set as index date). Comparison persons were not allowed to have $\mathrm{AD}$ (special reimbursement or antidementia drug dispensings) before the index date or during 12-month time period after it. If comparison person was diagnosed with $\mathrm{AD}$ during the follow-up he/she was censored from the persons without $\mathrm{AD}$ at that point.

\section{Comorbidities}

Data on comorbidities from 1972 until the index date were extracted from the Special Reimbursement and Hospital Discharge Registers. Diagnoses from the Special Reimbursement data included epilepsy, cardiovascular disease (coronary artery disease, arrhythmias, hypertension and heart failure), diabetes and asthma/chronic obstructive pulmonary disease (COPD). Diagnosis recorded in the Special Reimbursement register include both inpatient and outpatient care diagnoses which have been conducted according to prespecified diagnostic criteria approved and monitored by the Social Insurance Institution (as described for AD). Strokes (ICD-10 codes I6064), depression (F32-F34, F38-F39), schizophrenia $(\mathrm{F} 2 *)$, and mania/bipolar disorder (F30-F31) were identified from the Hospital Discharge register maintained by the National Institute of Health and Welfare. The dates of long-term institutionalization were obtained from the SII and durations of hospital stays from the Hospital Discharge register.

\section{Antiepileptic drugs}

Data on purchased drugs since 1995 were extracted from the Prescription register. This register contains records of all reimbursed drug purchases made by all Finnish community-dwelling residents and includes the dispensing date and Anatomical Therapeutic Chemical (ATC) code of each drug, the number of dispensed packages, and strength. These purchases have been modeled to use periods with a validated 


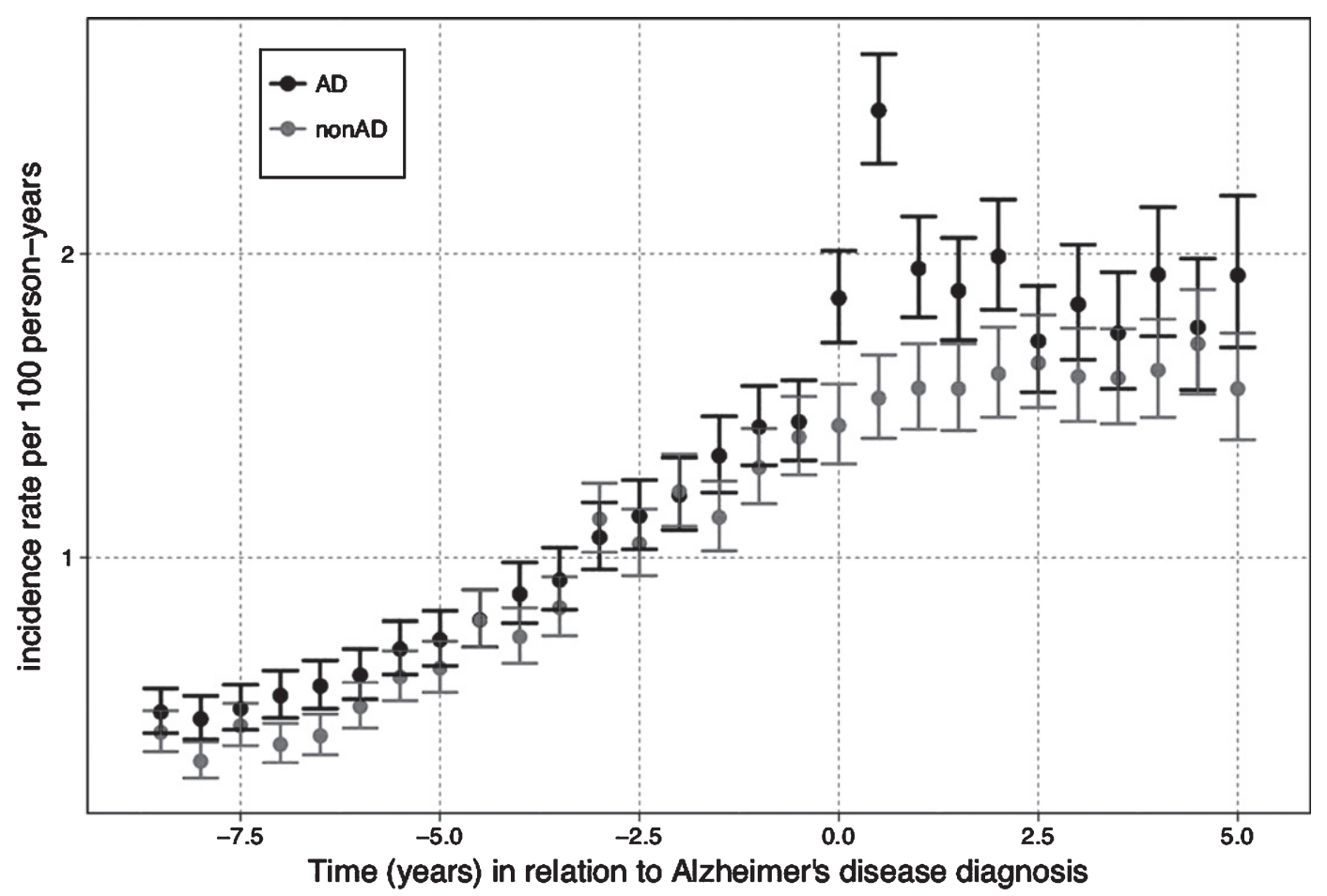

Fig. 1. The incidence of antiepileptic use in relation to Alzheimer's disease (AD) diagnosis.

PRE2DUP (from prescription drug purchases to drug use periods) method, by taking into account purchased amount in Defined Daily Doses (DDDs) and with the respect to hospitalizations, stockpiling, and dose changes $[10,11]$. The drugs have been classified according to the World Health Organization (WHO) ATC classification system. Antiepileptics comprised all drugs with the ATC code N03A. AEDs were categorized to older and newer according to previous classifications [12]. Older AEDs included primidone (ATC code N03AA03), carbamazepine (N03AF01), oxcarbazepine (N03AF02), clonazepam (N03AE01), phenytoin (N03AB02), and valproic acid (N03AG01), and newer AEDs included gabapentin (N03AX12), lamotrigine (N03AX09), levetiracetam (N03AX14), tiagabine (N03AG06), topiramate (N03AX11), vigabatrin (N03AG04), and pregabalin (N03AX16). Use of only one AED was considered as a monotherapy and concomitant use of more than one AED, regardless of the category, as polytherapy.

\section{Statistical analyses}

To derive incidence trajectories, incident AED use was identified by applying a one-year washout period 9-10 years before the index date. Persons using AEDs during the washout period, or being hospitalized or institutionalized for more than 182 days, or more than 90 days at the end of the washout period were excluded from the analyses (Supplementary Figure 1). After washout period, initiations of AED use diagnosis were followed-up in time from 9 years before and until 5 years after the index date. Persons were followed up until AED initiation (the event of interest possible only once for each person), death, continuous hospitalization/institutionalization more than 90 days (as drug use is not recorded in the Prescription register during hospital care), diagnoses of $\mathrm{AD}$ for comparison persons, or end of the data linkage (December 31, 2015), whichever occurred first. Incidence rates with $95 \%$ confidence intervals of AED use per 100 person-years were calculated for every six-month interval from nine years before to five years after $\mathrm{AD}$ diagnosis, separately for persons with and without $\mathrm{AD}$.

Prevalence was defined for groups stratified according to $\mathrm{AD}$ diagnoses as the number of persons using AEDs within every six-month intervals from nine years before to five years after AD diagnosis divided by the size of the group within each six-month period. 
Table 1

Characteristics of the study sample with and without Alzheimer's disease (AD) in relation to antiepileptic (AEDs) use at the time of AD diagnoses or corresponding matching date

\begin{tabular}{|c|c|c|c|c|c|c|}
\hline \multirow[t]{2}{*}{ Variables } & \multicolumn{2}{|c|}{$\mathrm{AD}(n=70,718)$} & \multirow[t]{2}{*}{$p$} & \multicolumn{2}{|c|}{ Non $\mathrm{AD}(n=70,718)$} & \multirow[t]{2}{*}{$p$} \\
\hline & $\begin{array}{c}\text { non-users } \\
(n=67,660)\end{array}$ & $\begin{array}{l}\text { AED users } \\
(n=3,058)\end{array}$ & & $\begin{array}{c}\text { non-users } \\
(n=68,463)\end{array}$ & $\begin{array}{l}\text { AED users } \\
(n=2,255)\end{array}$ & \\
\hline Age $(y)$, mean $\pm S D$ & $80.1 \pm 7.0$ & $78.3 \pm 8.0$ & $<0.001$ & $80.0 \pm 7.1$ & $80.5 \pm 6.8$ & 0.99 \\
\hline Women, $n(\%)$ & $44,286(65.4)$ & $1,830(59.8)$ & $<0.001$ & $44,613(65.2)$ & $1,500(66.5)$ & 0.18 \\
\hline \multicolumn{7}{|c|}{ Concomitant use of other medications $n(\%)$} \\
\hline Antidepressants & $13,001(19.2)$ & $994(32.5)$ & $<0.001$ & $5,356(7,8)$ & $541(24.0)$ & $<0.001$ \\
\hline Benzodiazepines & $14,506(21.4)$ & $1,046(34.2)$ & $<0.001$ & $14,171(20.7)$ & $801(35.5)$ & $<0.001$ \\
\hline Antipsychotics & $6,013(8.9)$ & $477(15.6)$ & $<0.001$ & $1,898(2.8)$ & $182(8.1)$ & $<0.001$ \\
\hline Opioids & $2,450(3.6)$ & 384 (12.6) & $<0.001$ & $2,927(4.3)$ & $406(18.0)$ & $<0.001$ \\
\hline NSAIDs $^{\mathrm{a}}$ & $5,491(8.1)$ & $373(12.2)$ & $<0.001$ & $6,829(10.1)$ & $351(15.6)$ & $<0.001$ \\
\hline \multicolumn{7}{|c|}{ Comorbidity diagnosis, $n(\%)$} \\
\hline Epilepsy & $390(0.6)$ & $1,066(34.9)$ & $<0.001$ & $342(0.5)$ & $601(26.6)$ & $<0.001$ \\
\hline Depression & $2,121(3.1)$ & $248(8.1)$ & $<0.001$ & $1,784(2.6)$ & $155(6.9)$ & $<0.001$ \\
\hline Schizophrenia & $971(1.4)$ & $108(3.5)$ & $<0.001$ & $863(1.3)$ & $70(3.1)$ & $<0.001$ \\
\hline Bipolar disorders & $2,215(3.3)$ & $280(9.2)$ & $<0.001$ & $1,845(2.7)$ & $179(7.9)$ & $<0.001$ \\
\hline Diabetes & $12,227(18.1)$ & $635(20.8)$ & $<0.001$ & $10,351(15.1)$ & $437(19.4)$ & $<0.001$ \\
\hline Cardiovascular disease & $19,451(28.8)$ & $1,005(32.9)$ & $<0.001$ & $18,927(27.6)$ & $741(32.9)$ & $<0.001$ \\
\hline Stroke & $6,562(9.7)$ & $643(21.0)$ & $<0.001$ & $5,562(8.1)$ & $436(19.3)$ & $<0.001$ \\
\hline Asthma/COPD ${ }^{\mathrm{b}}$ & $6,875(10.2)$ & $409(13.4)$ & $<0.001$ & $6,800(9.9)$ & $317(14.1)$ & $<0.001$ \\
\hline
\end{tabular}

ANOVA or Chi Square test were used to product the $p$-values. ${ }^{\mathrm{a} N S A I D s, ~ n o n-s t e r o i d a l ~ a n t i-i n f l a m m a t o r y ~ d r u g s ; ~}{ }^{\mathrm{b}} \mathrm{COPD}$, chronic obstructive pulmonary disease.

Additional analyses on the incidence of epilepsy diagnoses were conducted to demonstrate the impact of new epilepsy cases on the incidence of AED use. The similar design was used as for incidence of AED use, by excluding persons with epilepsy more than 9 years before $\mathrm{AD}$ diagnoses, and following up new diagnoses from nine years before until five years after the $\mathrm{AD}$ diagnoses.

Descriptive statistics were presented as means with standard deviations (SD). Chi-square tests were performed to assess differences in proportions and ANOVA was used for assessing differences in means. Analyses were performed with Stata (Version 14; StataCorp) and R 3.4 (R Core Team 2017).

\section{RESULTS}

\section{General characteristics}

Altogether $4.3 \%(n=3,058)$ persons with $\mathrm{AD}$ and $3.2 \%(n=2,255)$ without AD used AEDs at the time of AD diagnosis (Table 1). The mean age of AED users with AD was slightly lower than among AED users without $\mathrm{AD}$. Among $\mathrm{AED}$ users $34.9 \%$ of users with $\mathrm{AD}$ and $26.6 \%$ without $\mathrm{AD}$ had epilepsy diagnosis.

AED users with and without AD were more likely to use antidepressants, antipsychotics, benzodiazepines and related drugs, opioids as well as non-steroidal anti-inflammatory drugs (NSAIDs) compared to AED nonusers (Table 1). However, AED users with AD used more frequently antidepressants and antipsychotics, whereas use of opioids and NSAIDs was more prevalent among AED users without AD. Compared to non-users, AED users had more frequently chronic cardiovascular diseases, diabetes, mental and behavioral disorders such as depression and bipolar disorders (Table 1).

\section{Incidence of AED use}

The incidence of AED use gradually increased from approximately 0.5 initiations to 1.9 per 100 person-years among $\mathrm{AD}$ persons and from 0.4 to 1.4 per 100 person-years among persons without $A D$ from the beginning of follow-up until the time of $A D$ diagnosis (Fig. 1). Among persons with AD the AED initiation rate raised after $\mathrm{AD}$ diagnosis from approximately 1.9 initiations to 2.5 per 100 person-years, then lowered back to 1.9 initiations per 100 personyears to the end of the first year and stayed around the same level until the end of the follow-up. In persons without $\mathrm{AD}$, the incidence of AED use continued the same trajectory of the gradual grow until 1.5 initiations per 100 person-years during the first year after $\mathrm{AD}$ diagnosis and stayed around this level to the end of the follow-up (Fig. 1). 


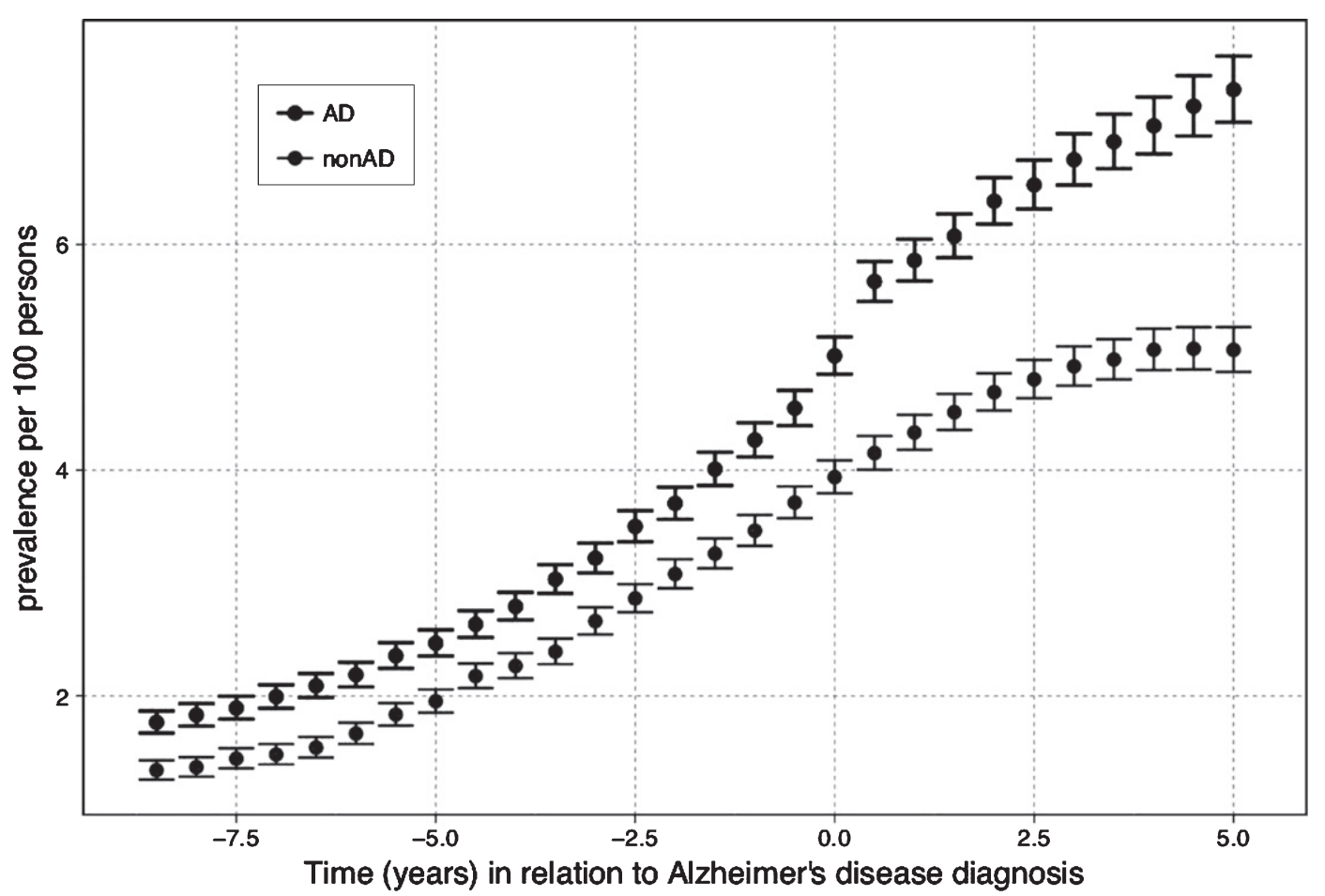

Fig. 2. The Prevalence of antiepileptic use in relation to Alzheimer's disease (AD) diagnosis.

\section{Prevalence of AED use}

The prevalence of AEDs use increased steadily from $1.8 \%$ to $5.0 \%$ in the $\mathrm{AD}$ and from $1.3 \%$ to $3.9 \%$ in the non-AD cohort before the AD diagnosis (Fig. 2). After AD diagnosis, the prevalence followed the same trend and reached the maximum of $7.4 \%$ in the $\mathrm{AD}$ cohort and $5.1 \%$ in the persons without $\mathrm{AD}$ to the end of the follow-up. The difference between cohorts was most evident at the end of the follow-up.

\section{Incidence of epilepsy}

Among persons with AD the incidence of epilepsy diagnosis started to increase two years before $A D$ diagnosis with the peak of 0.5 per 100 person-years 6 months after AD diagnosis (Fig. 3). Among persons without $\mathrm{AD}$ the incidence of epilepsy slightly increased during the follow-up with the maximum of approximately 0.15 per 100 person-years at the end of the follow-up.

\section{Types of AEDs}

Among AED users at the time of AD diagnosis the majority of $\mathrm{AD}$ and non- $\mathrm{AD}$ persons used new
AEDs $(46.5 \%$ in $\mathrm{AD}$ and $55.1 \%$ in non-AD population) (Table 2). Pregabalin was the most frequently used new AED (28.9\% with AD and $35.3 \%$ without $\mathrm{AD})$. Use of old AEDs was more frequent among persons with $\mathrm{AD}$ than without $\mathrm{AD}$. The most frequently used old $\mathrm{AEDs}$ among persons with $\mathrm{AD}$ was valproic acid followed by carbamazepine and clonazepam, whereas in the non-AD cohort the most frequently used old AED was carbamazepine followed by clonazepam and valproic acid.

In the $\mathrm{AD}$ cohort, treatment with AED polytherapy was also more frequent $9.2 \%$ compared to $5.3 \%$ among persons without AD (Table 2).

Characteristics of users of old and new AEDs are shown in Table 3. Users of new AEDs were more likely to use antidepressants, benzodiazepines, opioids, and NSAIDs and have more frequently diabetes than users of old AEDs, regardless of whether they had AD. In contrast, users of old AEDs were more likely to use antipsychotics and have a history of epilepsy, stroke, or mental and behavioral disorders more frequently than users of new AEDs in both $\mathrm{AD}$ and non-AD cohorts. Users of new AEDs were more likely to have cardiovascular diseases or asthma/COPD in the AD cohort. 


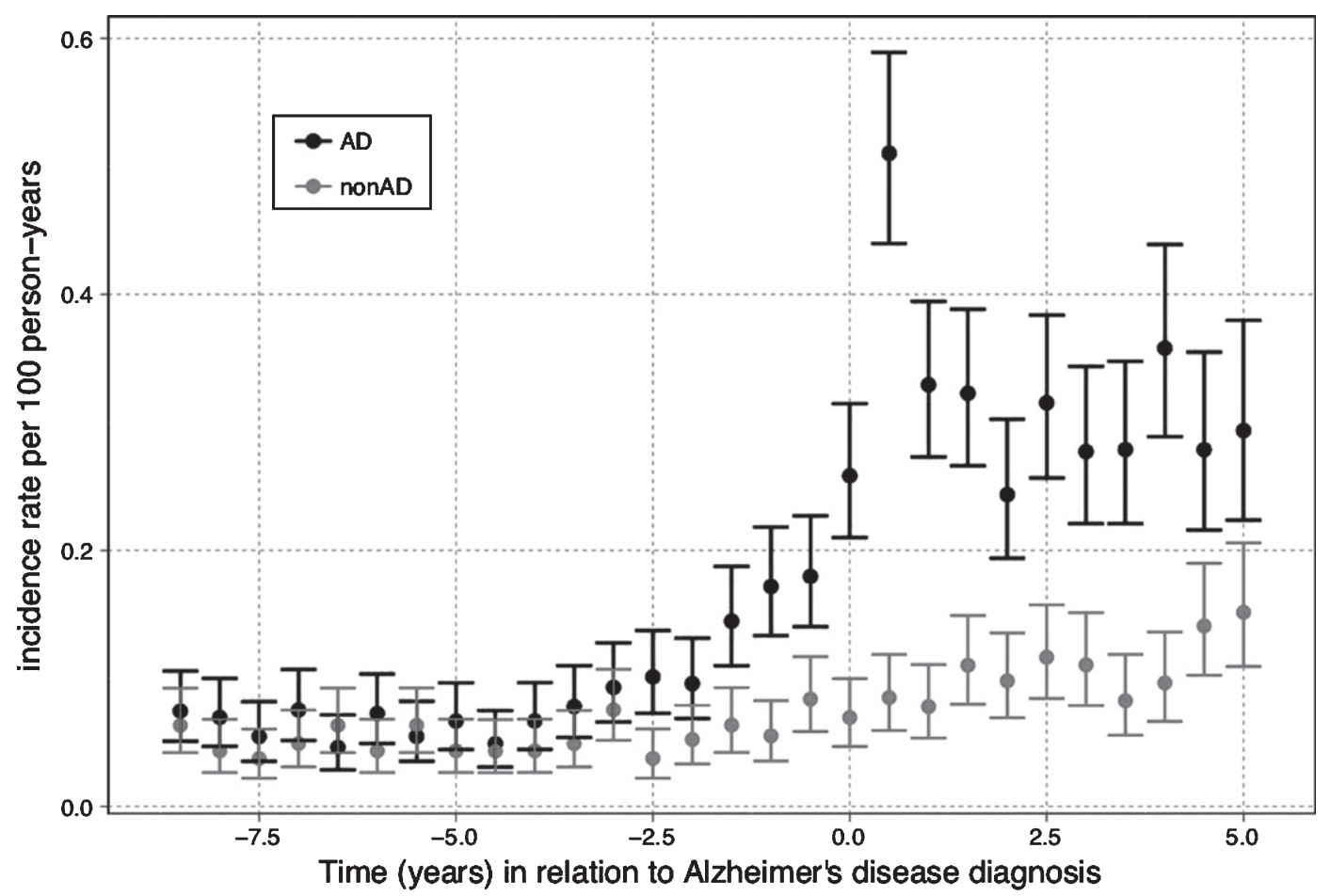

Fig. 3. The Incidence of epilepsy diagnosis in relation to Alzheimer's disease (AD) diagnosis.

Table 2

Antiepileptic drug use at the time of Alzheimer's disease diagnosis or corresponding matching date for persons with Alzheimer's disease

\begin{tabular}{lcc}
\hline Variables & $\mathrm{AD}$ & non AD \\
& $(n=3,058)$ & $(n=2,255)$ \\
\hline Old AEDs, monotherapy $n(\%)$ & $1,356(44.3)$ & $892(39.6)$ \\
Primidone & $5(0.2)$ & $5(0.2)$ \\
Phenytoin & $136(4.4)$ & $114(5.1)$ \\
Clonazepam & $298(9.7)$ & $243(10.8)$ \\
Carbamazepine & $452(14.8)$ & $364(16.1)$ \\
Valproic acid & $465(15.2)$ & $166(7.4)$ \\
New AEDs, monotherapy $n(\%)$ & $1,422(46.5)$ & $1,243(55.1)$ \\
Oxcarbazepine & $183(5.9)$ & $109(4.8)$ \\
Lamotrigine & $39(1.3)$ & $43(1.9)$ \\
Topiramite & $6(0.2)$ & $3(0.1)$ \\
Gabapentin & $289(9.4)$ & $267(11.8)$ \\
Levetiracetam & $26(0.8)$ & $26(1.2)$ \\
Pregabalin & $879(28.9)$ & $795(35.3)$ \\
Polytherapya $n(\%)$ & $280(9.2)$ & $120(5.3)$ \\
\hline AD, Alzhe &
\end{tabular}

AD, Alzheimer's Disease; AEDs, antiepileptic drugs; ${ }^{\text {a }}$ considered combinations within one type (old/new) of AEDs or across different types (old + new) of AEDs.

\section{DISCUSSION}

Our main finding is that among persons with and without $\mathrm{AD}$ the incidence and prevalence of AED use had an upward trend starting already several years before $\mathrm{AD}$ diagnosis and the same trend continued until the end of follow-up. At the time of AD diagnosis, persons with $\mathrm{AD}$ had higher prevalence and incidence of AED use compared with persons without AD. More frequent AED use among persons with AD was also reported in a previous Finnish study with data from 2005 [5] and according to findings of our study, the difference between persons with and without $\mathrm{AD}$ has increased since then. Although the incidence of epilepsy diagnoses increased concomitantly with incident AED use, it did not entirely explain the increase in the AED use as the increase in AED use was more pronounced.

The incidence of epilepsy diagnoses in our study is in accordance with previous observations where persons with $\mathrm{AD}$ have a higher incidence of seizures compared to persons with $\mathrm{AD}$ [13] and that the onset of unprovoked seizures starts already before cognitive problems and the dementia diagnosis $[14,15]$. It is important to acknowledge that only one third of unprovoked seizures in late-onset dementia, and less than every forth in early-onset dementia are epileptiformic seizures [15]. Thus, the differential diagnostics is demanding and it is possible that some incident epilepsy diagnoses in persons with $\mathrm{AD}$ in our study might not be correct ones. 
Table 3

Characteristics of the users of old and new AEDs in persons with and without Alzheimer's disease (AD) at the time of $\mathrm{AD}$ diagnosis (or corresponding matching date for the non- $\mathrm{AD}$ cohort)

\begin{tabular}{lcccccc}
\hline Variables & \multicolumn{2}{c}{ AD $(n=2,778)$} & $p$ & \multicolumn{2}{c}{ Non AD $(n=2,135)$} & $p$ \\
\cline { 2 - 4 } & $\begin{array}{c}\text { Old AED- } \\
\text { users } \\
(n=1,356)\end{array}$ & $\begin{array}{c}\text { New AED- } \\
\text { users } \\
(n=1,422)\end{array}$ & & $\begin{array}{c}\text { Old AED- } \\
\text { users } \\
(n=892)\end{array}$ & $\begin{array}{c}\text { New AED- } \\
\text { users } \\
(n=1,243)\end{array}$ \\
\hline Age (years), mean \pm SD & $77.05 \pm 8.2$ & $80.0 \pm 7.1$ & $<0.001$ & $79.67 \pm 7.0$ & $81.3 \pm 6.7$ & $<0.001$ \\
Women, $n(\%)$ & $770(56.8)$ & $901(63.4)$ & $<0.001$ & $536(60.1)$ & $897(72.2)$ & $<0.001$ \\
Concomitant use of other & & & & & & \\
medications $n(\%)$ & & & & & & \\
Antidepressants & $388(28.6)$ & $544(38.3)$ & $<0.001$ & $179(20,1)$ & $333(26.8)$ & $<0.001$ \\
Benzodiazepines & $393(29.0)$ & $570(40.1)$ & $<0.001$ & $261(29.3)$ & $500(40.2)$ & $<0.001$ \\
Antipsychotics & $257(19.0)$ & $172(12.1)$ & $<0.001$ & $97(10.9)$ & $78(6.3)$ & $<0.001$ \\
Opioids & $61(4.5)$ & $298(21.0)$ & $<0.001$ & $66(7.4)$ & $319(25.7)$ & $<0.001$ \\
NSAIDsa & $125(9.2)$ & $206(14.5)$ & $<0.001$ & $115(12.9)$ & $217(17.5)$ & $<0.001$ \\
Comorbidity diagnosis, $n(\%)$ & & & & & & \\
Epilepsy & $668(49.3)$ & $199(14.0)$ & $<0.001$ & $388(43.5)$ & $146(11.8)$ & $<0.001$ \\
Depression & $126(9.3)$ & $99(7.0)$ & 0.024 & $78(8.7)$ & $70(5.6)$ & 0.005 \\
Schizophrenia & $75(5.5)$ & $23(1.6)$ & $<0.001$ & $50(5.6)$ & $17(1.4)$ & $<0.001$ \\
Bipolar disorders & $155(11.4)$ & $102(7.2)$ & $<0.001$ & $95(10.7)$ & $76(6.1)$ & $<0.001$ \\
Diabetes & $228(16.8)$ & $360(25.3)$ & $<0.001$ & $141(15.8)$ & $282(22.7)$ & $<0.001$ \\
Cardiovascular disease & $427(31.5)$ & $501(35.2)$ & 0.037 & $273(30.6)$ & $425(34.2)$ & 0.081 \\
Stroke & $322(23.8)$ & $242(17.0)$ & $<0.001$ & $203(22.8)$ & $207(16.7)$ & $<0.001$ \\
Asthma/COPDb & $156(11.5)$ & $220(15.5)$ & 0.002 & $129(14.5)$ & $174(14.0)$ & 0.762 \\
\hline
\end{tabular}

ANOVA or Chi Square test were used to product the $p$-values. ${ }^{a}$ NSAIDs, non-steroidal anti-inflammatory drugs;

${ }^{\mathrm{b}} \mathrm{COPD}$, chronic obstructive pulmonary disease.

The increase in the incidence of AED use already before and at the time of $\mathrm{AD}$ diagnosis might be explained by occurrence of prodromal symptoms which were treated with AEDs. Our previous findings on the increase in psychotropic drug use support this hypothesis about prodromal symptoms affecting AED use around AD diagnosis [16, 17]. AEDs are commonly used for indications other than epilepsy, such as neuropathic pain, bipolar disorders, and migraine [3, 18-20]. In our study, the majority of AED users with and without AD used new AEDs, with pregabalin being the most frequent drug followed by gabapentin. Pregabalin and gabapentin are mainly used for neuropathic pain and occasionally for generalized anxiety disorder in older population [20-23]. Thus, it is likely that the majority of persons used AEDs due to other indications than epilepsy. This is also supported by the differences in characteristics of AED users and nonusers, as well as users of old and new AEDs. Our results are contrary to findings in general population, where the main indication for AEDs was epilepsy [19]. The difference can be explained by younger population and by the time the study was conducted, just after the new AEDs came to the market.

Among AED users, persons with AD used more frequently old AEDs than persons without $\mathrm{AD}$. The biggest difference was in the use of valproic acid, which was more frequent among persons with $\mathrm{AD}$. Valproic acid is recommended as first-line therapy for epilepsy in persons with cognitive disorder according to the current Finnish guidelines [24]. In addition, it is the most frequently used AED in older persons with epilepsy in Finland [25]. Valproic acid has been used for behavioral and psychological symptoms of dementia [26], although it is not recommended due to lack of efficacy and possible adverse effects. Carbamazepine was the most commonly used drug among persons without $\mathrm{AD}$, presumably for epilepsy [18, 19]. In the recent guidelines, carbamazepine, valproic acid, and phenytoin are recommended as a first line therapy for generalized and focal seizures in adults [27, 28]. The use of carbamazepine and valproic acid might also be explained by their use as moodstabilizers in bipolar relapse prevention [29, 30]. The higher prevalence of bipolar diagnosis among AED users supports this hypothesis.

A strength of our study is that it covers all community dwelling persons with AD in Finland. Thus, the study cohort is generally representative, although the results may not be generalizable to persons living in institutional care. We utilized the data on purchased drugs instead of self- /or proxy-reported data, or data on merely prescribed drugs. However, 
the Prescription register does not contain records of drugs used in hospitals or institutional care and it does not provide the information whether the purchased drugs were actually used. In addition, the indications of AEDs use were not available, and it is possible that some of the persons with epilepsy used AEDs for other indications. To describe possible indication for epilepsy, we reported the incidence of epilepsy in relation to $\mathrm{AD}$ diagnosis date. The $\mathrm{AD}$ and epilepsy diagnoses were validated in terms of steps required to verify the diagnosis with the SII. However, we were not able to describe the use of AEDs in relation to types and severity of epilepsy.

Our findings have clinical implications, because older persons and especially persons with AD may be susceptible to the adverse effects and events of older AEDs [6, 7] and, moreover, to cognitive and motor impairments [31-33]. Old AEDs such as carbamazepine have a narrow therapeutic window and multiple potential pharmacokinetic drug-drug interactions $[34,35]$. This is especially a matter of concern for persons with $\mathrm{AD}$, who use higher number of drugs than persons without $\mathrm{AD}$. It is important to acknowledge that AED treatment for epilepsy or other indications such as bipolar disorders or neuropathic pain is often necessary, and abrupt changes or discontinuations should be avoided [23, $36,37]$.

In conclusion, among persons with and without $\mathrm{AD}$ the incidence and prevalence of AED use had an upward trend already several years before $\mathrm{AD}$ diagnosis and the same trend continued to the end of follow-up. As the majority of AED users did not have epilepsy, AEDs were mostly used for other indications. Persons with AD used old AEDs more frequently than those without $\mathrm{AD}$, despite their possible adverse effects. Careful clinical consideration is needed before prescribing AEDs to an older person with or without $\mathrm{AD}$.

\section{ACKNOWLEDGMENTS}

A.M.T. is funded by Academy of Finland (grants 307232 which paid for T.S.'s salary and 295334), H.T. and A.M.T. acknowledge strategic funding from the University of Eastern Finland.

The sponsor had no role in the design, methods, data collection, analysis and preparation of paper.

Authors' disclosures available online (https:// www.j-alz.com/manuscript-disclosures/18-0594r1).

\section{SUPPLEMENTARY MATERIAL}

The supplementary material is available in the electronic version of this article: http://dx.doi.org/ 10.3233/JAD-180594.

\section{REFERENCES}

[1] Galimberti CA, Magri F, Magnani B, Arbasino C, Cravello L, Marchioni E, Tartara A (2006) Antiepileptic drug use and epileptic seizures in elderly nursing home residents: A survey in the province of Pavia, Northern Italy. Epilepsy Res 68, 1-8.

[2] Lackner TE, Cloyd JC, Thomas LW, Leppik IE (1998) Antiepileptic drug use in nursing home residents: Effect of age, gender, and comedication on patterns of use. Epilepsia 39, 1083-1087.

[3] Oteri A, Trifiro G, Gagliostro MS, Tari DU, Moretti S, Bramanti P, Spina E, Caputi AP, Arcoraci V (2010) Prescribing pattern of anti-epileptic drugs in an Italian setting of elderly outpatients: A population-based study during 2004-07. Br J Clin Pharmacol 70, 514-522.

[4] Johnell K, Fastbom J (2011) Antiepileptic drug use in community-dwelling and institutionalized elderly: A nationwide study of over 1,300,000 older people. Eur J Clin Pharmacol 67, 1069-1075.

[5] Bell JS, Lonnroos E, Koivisto AM, Lavikainen P, Laitinen ML, Soininen H, Hartikainen S (2011) Use of antiepileptic drugs among community-dwelling persons with Alzheimer's disease in Finland. J Alzheimers Dis 26, 231-237.

[6] Giorgi FS, Guida M, Vergallo A, Bonuccelli U, Zaccara G (2017) Treatment of epilepsy in patients with Alzheimer's disease. Expert Rev Neurother 17, 309-318.

[7] Hommet C, Mondon K, Camus V, De Toffol B, Constans T (2008) Epilepsy and dementia in the elderly. Dement Geriatr Cogn Disord 25, 293-300.

[8] Tolppanen AM, Taipale H, Koponen M, Lavikainen P, Tanskanen A, Tiihonen J, Hartikainen S (2016) Cohort profile: The Finnish Medication and Alzheimer's disease (MEDALZ) study. BMJ Open 6, e012100.

[9] McKhann GM, Knopman DS, Chertkow H, Hyman BT, Jack CR, Kawas CH, Klunk WE, Koroshetz WJ, Manly JJ, Mayeux R, Mohs RC, Morris JC, Rossor MN, Scheltens P, Carrillo MC, Thies B, Weintraub S, Phelps $\mathrm{CH}$ (2011) The diagnosis of dementia due to Alzheimer's disease: Recommendations from the National Institute on Aging-Alzheimer's Association workgroups on diagnostic guidelines for Alzheimer's disease. Alzheimers Dementia 7, 263-269.

[10] Tanskanen A, Taipale H, Koponen M, Tolppanen AM, Hartikainen S, Ahonen R, Tiihonen J (2015) From prescription drug purchases to drug use periods - a second generation method (PRE2DUP). BMC Med Inform Decis Mak 15, 21.

[11] Taipale H, Tanskanen A, Koponen M, Tolppanen AM, Tiihonen J, Hartikainen S (2016) Agreement between PRE2DUP register data modeling method and comprehensive drug use interview among older persons. Clin Epidemiol 8, 363-371.

[12] Lee SK (2014) Old versus new: Why do we need new antiepileptic drugs? J Epilepsy Res 4, 39-44.

[13] Beagle AJ, Darwish SM, Ranasinghe KG, La AL, Karageorgiou E, Vossel KA (2017) Relative incidence of seizures 
and myoclonus in Alzheimer's disease, dementia with Lewy bodies, and frontotemporal dementia. J Alzheimers Dis $\mathbf{6 0}$, 211-223.

[14] Amatniek JC, Hauser WA, DelCastillo-Castaneda C, Jacobs DM, Marder K, Bell K, Albert M, Brandt J, Stern Y (2006) Incidence and predictors of seizures in patients with Alzheimer's disease. Epilepsia 47, 867-872.

[15] Sarkis RA, Dickerson BC, Cole AJ, Chemali ZN (2016) Clinical and neurophysiologic characteristics of unprovoked seizures in patients diagnosed with dementia. J Neuropsychiatry Clin Neurosci 28, 56-61.

[16] Koponen M, Tolppanen AM, Taipale H, Tanskanen A, Tiihonen J, Johnell K, Fastbom J, Ahonen R, Hartikainen S (2015) Incidence of antipsychotic use in relation to diagnosis of Alzheimer's disease among community-dwelling persons. Br J Psychiatry 207, 444-449.

[17] Puranen A, Taipale H, Koponen M, Tanskanen A, Tolppanen AM, Tiihonen J, Hartikainen S (2017) Incidence of antidepressant use in community-dwelling persons with and without Alzheimer's disease: 13-year follow-up. Int J Geriatr Psychiatry 32, 94-101.

[18] Hsieh LP, Huang CY (2011) Trends in the use of antiepileptic drugs in Taiwan from 2003 to 2007: A population-based national health insurance study. Epilepsy Res 96, 81-88.

[19] Johannessen Landmark C, Larsson PG, Rytter E, Johannessen SI (2009) Antiepileptic drugs in epilepsy and other disorders-a population-based study of prescriptions. Epilepsy Res 87, 31-39.

[20] Wettermark B, Brandt L, Kieler H, Boden R (2014) Pregabalin is increasingly prescribed for neuropathic pain, generalised anxiety disorder and epilepsy but many patients discontinue treatment. Int J Clin Pract 68, 104-110.

[21] Tassone DM, Boyce E, Guyer J, Nuzum D (2007) Pregabalin: A novel gamma-aminobutyric acid analogue in the treatment of neuropathic pain, partial-onset seizures, and anxiety disorders. Clin Ther 29, 26-48.

[22] Ben-Menachem E (2004) Pregabalin pharmacology and its relevance to clinical practice. Epilepsia 45(Suppl 6), 13-18.

[23] Hitiris N, Brodie MJ (2006) Modern antiepileptic drugs: Guidelines and beyond. Curr Opin Neurol 19, 175-180.

[24] The Finnish Medical Society Duodecim (2018) Epilepsies (adult). Current Care Guidelines, http://www.kaypahoito. fi/web/english/guidelineabstracts/guideline?id=ccs00054

[25] Bruun E, Virta LJ, Kalviainen R, Keranen T (2015) Choice of the first anti-epileptic drug in elderly patients with newly diagnosed epilepsy: A Finnish retrospective study. Seizure 31, 27-32.
[26] Rabins PV, Blacker D, Rovner BW, Rummans T, Schneider LS, Tariot PN, Blass DM, McIntyre JS, Charles SC, Anzia DJ, Cook IA, Finnerty MT, Johnson BR, Nininger JE, Schneidman B, Summergrad P, Woods SM, Berger J, Cross CD, Brandt HA, Margolis PM, Shemo JP, Blinder BJ, Duncan DL, Barnovitz MA, Carino AJ, Freyberg ZZ, Gray SH, Tonnu T, Kunkle R, Albert AB, Craig TJ, Regier DA, Fochtmann LJ (2007) American Psychiatric Association practice guideline for the treatment of patients with Alzheimer's disease and other dementias. Second edition. Am J Psychiatry 164, 5-56.

[27] Glauser T, Ben-Menachem E, Bourgeois B, Cnaan A, Guerreiro C, Kalviainen R, Mattson R, French JA, Perucca E, Tomson T (2013) Updated ILAE evidence review of antiepileptic drug efficacy and effectiveness as initial monotherapy for epileptic seizures and syndromes. Epilepsia 54, 551-563.

[28] National Institute for Health and Care Excellence, Epilepsies: Diagnosis and management, https://www.nice. org.uk/guidance/cg137

[29] Bialer M (2012) Why are antiepileptic drugs used for nonepileptic conditions? Epilepsia 53(Suppl 7), 26-33.

[30] Spina E, Perugi G (2004) Antiepileptic drugs: Indications other than epilepsy. Epileptic Disord 6, 57-75.

[31] Mahmoud F, Tampi RR (2011) Valproic acid-induced parkinsonism in the elderly: A comprehensive review of the literature. Am J Geriatr Pharmacother 9, 405-412.

[32] Tsai PS, Liu IC, Chiu CH, Huang CJ, Wang MY (2016) Effect of valproic acid on dementia onset in patients with bipolar disorder. J Affect Disord 201, 131-136.

[33] Ortinski P, Meador KJ (2004) Cognitive side effects of antiepileptic drugs. Epilepsy Behav 5(Suppl 1), S60-S65.

[34] Ferlazzo E, Sueri C, Gasparini S, Aguglia U (2016) Challenges in the pharmacological management of epilepsy and its causes in the elderly. Pharmacol Res 106, 21-26.

[35] Greenberg RG, Melloni C, Wu H, Gonzalez D, Ku L, Hill KD, Hornik CP, Cohen-Wolkowiez M, Guptill JT (2016) Therapeutic index estimation of antiepileptic drugs: A systematic literature review approach. Clin Neuropharmacol 39, 232-240.

[36] Jankovic SM, Dostic M (2012) Choice of antiepileptic drugs for the elderly: Possible drug interactions and adverse effects. Expert Opin Drug Metab Toxicol 8, 81-91.

[37] Ossemann M, Bruls E, de Borchgrave V, De Cock C, Delcourt C, Delvaux V, Depondt C, de Tourchaninoff M, Grisar T, Legros B, Lienard F, Lievens I, Sadzot B, van Rijckevorsel $\mathrm{K}$ (2006) Guidelines for the management of epilepsy in the elderly. Acta Neurol Belg 106, 111-116. 